San Jose State University

SJSU ScholarWorks

Master's Projects

Master's Theses and Graduate Research

5-18-2005

\title{
Self-Efficacy and Sexual Transmitted Disease Prevention Among College Women
}

Dominique M. Ly

San Jose State University

Follow this and additional works at: https://scholarworks.sjsu.edu/etd_projects

Part of the Other Nursing Commons

\section{Recommended Citation}

Ly, Dominique M., "Self-Efficacy and Sexual Transmitted Disease Prevention Among College Women" (2005). Master's Projects. 785.

DOI: https://doi.org/10.31979/etd.ttrh-n88j

https://scholarworks.sjsu.edu/etd_projects/785

This Master's Project is brought to you for free and open access by the Master's Theses and Graduate Research at SJSU ScholarWorks. It has been accepted for inclusion in Master's Projects by an authorized administrator of SJSU ScholarWorks. For more information, please contact scholarworks@sjsu.edu. 
Self-efficacy 1

Self-Efficacy and Sexual Transmitted Disease Prevention Among College Women

\author{
A Research Manuscript \\ Presented to \\ The Faculty of the School of Nursing \\ San Jose State University \\ In Partial Fulfillment \\ Of the Requirements for the Degree \\ Master of Science
}

Dominique M. Ly

May $18^{\text {th }}, 2005$ 
Self-efficacy 2

\begin{abstract}
According to the Center of Disease Control (2002), sexual transmitted diseases (STDs) are on the rise, especially among women. By far, women bear the greatest burden of STDs because they suffer more frequently and develop more serious complications than men. This study explored the relationship between self-efficacy and safe sex behaviors among college women. The data was collected by using questionnaires from the General Perceived Self-Efficacy Scale (GPSE) and the Condom Use Self-Efficacy Scale (CUSES). The sample was composed of 38 unmarried female college students between the ages of 18 and 25 years-of-age who had been sexually active within the last 3 months. It was expected that women who have high score in GPSE would be more likely to engage in safe sex. The findings indicated there was no correlation between self-efficacy and safe sex practice.
\end{abstract}


Introduction

\section{$\underline{\text { Research Problem }}$}

Each year, 12 million new cases of sexually transmitted diseases (STDs) occur, and two thirds of those individuals infected are under the age of 25 years of age [Centers for Disease Control and Prevention (CDC), 2000]. Sexually transmitted diseases are hidden epidemics of tremendous health and economic consequence in the United States. They are hidden from public view because many Americans are reluctant to discuss sexual health issues in an open way and because of the social stigma associated with the diseases.

Of the top 10 most frequently reported diseases in 1992 in the United States, 5 are STDs. (Basen-Engquist, 1992). Since the 1970s, in the United States the incidence of STDs including human immunodeficiency virus infection (HIV) and acquired immunodeficiency syndrome (AIDS) among young adults has dramatically increased. STD infections such as gonorrhea, chlamydia, vaginal warts, pelvic inflammatory diseases (PIDs), and herpes are also occurring at an alarming rate in the United States among young adults (Grimley, Riley, Bellis, \& Prochaska, 1993). According to CDC statistic and surveillance in 2003, there was an increase of chlamydia infection compared to 2002. Rates of reported chlamydia among women have been increasing annually since the last few months of 1980 . Rates of gonorrhea in women are particularly high in the 15 to 19-year-old age group. Also the rate of primary and secondary syphilis has increased each year since 2001 (CDC, 2003). 
Women bear the greater burden of STDs because they may not have symptoms and may develop more serious complications than men. Women between 18 and 25 years of age are at greater risk than their male counterparts (CDC, 2000). Women are particularly vulnerable, because they are more biologically susceptible to certain sexually transmitted infections such as chlamydia, than men. Untreated chlamydia in women may develop into pelvic inflammatory disease that may lead to infertility. Women are also more likely to have asymptomatic infections that commonly result in delayed diagnosis and treatment (Basen-Engquist, 1992). From 1973 through 1992, more than 150,000 women in the United States died of causes associated with STDs and their complications. Incidence of STDs among female college students increased from $8 \%$ in 1992 to $25 \%$ in 1995 (Cobb, 1997). In 2000, the overall reported rate of chlamydia infection the United States among women was four times the reported rate among men. According to National Vital Statistics Reports in 2005, HIV disease is the $14^{\text {th }}$ leading cause of death in the United States. The Black population has the highest percentage of HIV among all races.

Traditional gender roles include the expectation that women adopt a sexually passive role. Women often do not take the opportunity to assert themselves in behalf of their own sexual interests. Therefore, in complying with an expectation of sexual passivity, women may be reluctant to refuse unwanted sex (Cecil \& Pinkerton, 1998). According to Morokoff et al. (1997), college women are concerned about hurting their partners' feelings if they refuse intercourse. There is sufficient evidence that women do not engage in adequate preventive behaviors. For example, over the past several years, 
women have become the fastest growing group of people with acquired immunodeficiency syndrome (Morokoff et al., 1997).

Sexually transmitted diseases are associated with both direct and indirect costs.

Direct costs include expenditures for medical services such as physician services, laboratory services, hospitalization, transportation, and medical supplies. Indirect costs mainly include lost wages due to illness. It estimated that the direct and indirect costs of selected major STDs are approximately $\$ 10$ billion annually (CDC, 2000). Sexual transmitted diseases represent a growing threat to the nation's health. Nearly all STDs are acquired through behaviors that can be avoided or modified.

Why are awareness of serious risk and adequate knowledge of STD prevention apparently insufficient to keep the infection rates down? People may know how the infections are transmitted but they still engage in unprotected sexual intercourse. According to Bandura's self-efficacy theory, people become infected because behavior is not the direct result of knowledge or skills. However, it is rather mediated by a process of cognitive appraisal by which people integrate knowledge, outcome expectancies, emotional states, social influences, and past experiences to form a judgement of their ability to master a difficult situation (Wulfert \& Wan, 1993).

\section{Purpose of the Study}

There are limited studies that focus on the relationship between self-efficacy and safe sex practices. Given the risks for STD transmission among college-age women, and the fact that widespread knowledge of STDs has failed to reduce risk behaviors, the rates of STDs remain high. Therefore, the purpose of this study is to explore the relationship between self-efficacy and safe sex behaviors among college women. According to Cecil 
and Pinkerton (1998), self-efficacy refers to a person's beliefs concerning how capable she (or he) is of performing specific actions that result in specific outcomes. Safe sex behavior is defined as using a condom consistently within the last 3 months as a contraceptive to prevent an STD infection.

\section{Background Literature Review}

Hale and Trumbetta's study in 1996 attempted to examine how accurately college women perceived their risk for STD infection, and how self-efficacy was related to STD risk prevention behaviors. A convenience sample of 400 college women was obtained from the university health center gynecology clinic. The results provided evidence that the women's knowledge of STD transmission and prevention was consistently high compared to prior studies. The researchers found that there was a discrepancy among college women between their low perceived risk of acquiring STDs and their actual behavioral risk. Women reported that they knew that STD transmission was possible via unprotected oral sex. However, they failed to take precautions with oral sex and still responded that their chance of getting STDs was low. College women responded that they did have an adequate knowledge about how to prevent STDs but their behavior did not reflect this knowledge. Over half the sample reported inconsistent use of condoms and one fourth reported never using a condom during sexual intercourse. Hale and Trumbetta recommended further study of self-efficacy and STD prevention behaviors through modeling techniques such as condom use.

Cecil and Pinkerton (1998) used the psychometric properties of a 22-item instrument assessing the correlation between the self-efficacy subscale scores for refusing sexual intercourse, questioning potential partners, and using a condom to the scores on 
measures of sexual behaviors including numbers of partners, condom use behavior, pregnancy, and STD history. They found a low score on the self-efficacy subscale for refusing sexual intercourse. Many respondents reported high confidence in their ability to perform target behaviors consisting of using condom and questioning potential partners. Cecil and Pinkerton concluded that it is important to enhance self-efficacy through improving condom use and that it would be an effective way to reduce the rate of STDs among college women.

The need to develop and implement effective programs to prevent STDs among college women is now widely recognized. O'Leary, Goodhart, Jemmott, and BoccherLattimore (1992) explored the utility of variables from social cognitive theory in predicting safe sex practices among college students in New Jersey. A sample of 923 students from 4 college campuses in New Jersey was recruited. The authors expected that the frequent use of condom during sexual intercourse would be related to: (a) more knowledge concerning AIDS, (b) greater perceived potential risk, (c) perceptions of more positive social norms for safe sex behavior, (d) fewer negative expected outcomes of condom use, (e) strong perceived self-efficacy to discuss history and to perform safer behaviors, and ( $\mathrm{f}$ ) less frequent use of alcohol and other drugs in combination with sex. O'Leary et al. found that negative outcomes expectancies regarding condom use and self-efficacy to practice safe sex were the major factors influencing condom usage. Self-efficacy beliefs were influenced in 4 different ways. These 4 ways were through: (a) persuasion, (b) vicarious performance, (c) actual mastering experiences, and (d) physiological arousal levels. O'Leary et al. found that performance mastery is the most powerful of all 4 , followed by vicarious mastery. Therefore condom use skills could 
be demonstrated through vicarious mastery in which students put condoms on penis models. O'Leary et al. concluded that the social cognitive theory plays an important role in determining safe sexual practices among college students.

According to Heinrich (1993) college student's contraceptive behavior does not reflect their level of education and the availability of contraceptive services. Heinrich's study in 1993 examined the relationship between the self-efficacy and its effect on contraceptive use in the female college population. Heinrich concluded that knowledge was significantly correlated with effective use of contraceptives and self-efficacy in comparison with other studies that have found that low birth control knowledge was correlated with non-use of contraceptive. College women who are young, less sexual active, less knowledgeable, and uncomfortable with birth control were at greater risk for ineffective contraceptive use. Heinrich's findings suggested that there was a correlation between contraceptive self-efficacy and effective contraceptive behavior and that contraceptive self-efficacy was predictive of contraceptive behavior.

Schuster (1998) used the Social Cognitive Theory to determine the condom use among college students. Schuster's sample included college students who were older and more ethnicity diverse than the average college student. However, Schuster found that women scored low on their physical and emotional outcome expectations of using a condom. The findings suggested that it was important to gain self-efficacy because it was related to assertiveness.

Bengel, Belz-Merk, and Farin (1996) tested the important of specific forms of self-efficacy and outcome expectancy. The findings showed that the perceived danger of AIDS had little predictive value with regard to the use of protective measures. 
Bengel et al.'s finding was consistent with other studies. Bengel et al. emphasized in their conclusion that in order to promote protective behavior an individual's self-efficacy needs to be addressed.

Hankins (1998) recommended that more studies needed to examine cultural, socio-economic, and contextual factors. Hankins' concluded that risk perception and self-efficacy influence behavioral change but structural and contextual factors influence prevention programs and treatment of STDs.

\section{Theoretical Framework}

The theoretical framework used in this study was based on a component of Bandura's Social Cognitive Theory. The construct that is crucial to this study is self-efficacy. Self-efficacy has been shown to be a factor in changing health behaviors such as smoking cessation, weight control, exercise, nutrition, and alcohol use. Health promotion programs that enhance self-efficacy foster healthy behaviors ( $O^{\prime}$ Leary, 1985). Self-efficacy is defined as an individual's belief in her or his capability to organize and execute a course of action needed to deal with a prospective situation (Mailbach \& Murphy, 1995). Self-efficacy is divided into two components. The first component is outcome expectancy and the second component is efficacy expectation. Outcome expectancy is a person's belief that a given behavior will lead to certain outcome. Efficacy expectation is a person's beliefs about her/his capability to produce a particular behavior (Mailbach \& Murphy, 1995). For example, students who earn high grades have the advantage of being more likely to get admitted to medical school. However, not all students with high grades choose to go to medical school because some of them may not 
want to be doctors or may doubt themselves and do not believe that they can master the science requirements for medical school.

Bandura (1977) further breaks efficacy into four major sources; they are:

(a) performance accomplishments, (b) vicarious experience, (c) verbal persuasion, and

(d) emotional arousal. Performance accomplishments are based on personal experience.

Successes from personal experiences raise expectations of further success; on the other hand, failures will lower these expectations. Vicarious experience relies on lives models. Watching others perform threatening activities without hurting themselves motivates observers so that they can also master the performance if they persist in their efforts. Verbal persuasion works by suggesting to a person that she or he can cope with what has been overwhelming in the past. Verbal persuasion is the least likely to increase efficacy expectations because verbal persuasion is not based on experience. Emotional arousal is related to the assumption that high arousal adversely affects performance.

Self-efficacy beliefs have been adapted for enhancement of disease prevention and of health promoting behaviors. Mailbach and Murphy (1995) discuss efficacy beliefs in the context of 4 categories: (a) choice behavior, (b) effort expenditure and persistence, (c) thought pattern, and (d) emotional reaction. Choice behavior refers to the day-to-day choices people make regarding health. Choice behavior suggests that an individual with a low self-efficacy belief may not adopt safe sex practices. New behaviors require both effort expenditure and persistence. High self-efficacy motivates people to make a strong commitment and to expend effort when engaging in a new activity. When obstacles are encountered, people with high self-efficacy persist to work harder to overcome difficulties. Efficacy beliefs also affect thought patterns. High efficacy supports goals and 
aspirations. Low efficacy causes people to doubt themselves. High efficacy encourages people to visualize positive performance. Low efficacy encourages people to visualize negative performance. Self-efficacy also influences the affective states. In coping with a difficult time, people with low self-efficacy are more vulnerable to stress and depression. Mailbach and Murphy's study demonstrated that self-efficacy is associated with changing to more positive health behaviors. Self-judgments of efficacy determine in which activity to engage or avoid (O'Leary, 1985). Practicing safe sex will be affected by one's judgment of self-efficacy. In general the greater the self-efficacy the safer the behavior (Hale \& Trumbetta, 1996).

\section{Methodology}

\section{Research Design/Subjects and Sampling}

This study explored the relationship between self-efficacy and safe sex practices. Data were collected using a survey with questionnaires from the General Perceived SelfEfficacy Scale (GPSES), the Condom Use Self-Efficacy Scale (CUSES), and demographic questions. This study used a quantitative non-experimental cross-sectional design. A sample of 38 unmarried female students volunteer between the ages of 18 to 25 years of age from a University in California. The study received approval from the Human Subjects-Institutional Review Board (IRB) on the campus. The participants were recruited on the first floor lobby of the Health Building on 3 days from 12 Noon to 2 PM on the first two days and from 2 PM to 4 PM on the last day. The criteria for participation were that the volunteer be female, between 18-25 years of age, unmarried, and sexually active within the last 3 months. Participation was strictly volunteer. Volunteer subjects received 1 package of free condoms as an incentive to participate in the study. The survey 
was distributed to qualified volunteers who walked into the lobby of the Health Building. The participants completed the survey and the consent and returned it in a sealed envelop. $\underline{\text { Instruments }}$

Self-efficacy was measured using the General Perceived Self-Efficacy Scale (GPSES) that was developed by Ralf Schwarzer and Matthias Jerusalem in 1993 and later adapted and revised to 29 other languages. The scale consists of 10 items. Response options are on a 4-point Likert scale ranging from "not at all true" (scored as 1) to "exactly true" (scored as 4). This scale is available in the public domain and can be obtained from the Internet at www.yorku.ca/.faculty/academic/schwarze/engscal.htl.

Safe sex behavior was measured using The Condom Use Self-Efficacy Scale (CUSES). The scale was developed by Linda Bradfford and Kenneth Beck in 1991. The authors of the scale gave the researcher the permission to use the tool. The CUSES consists of 28 items that comprise 4 subscales: mechanics, partner disapproval, assertive, and intoxicants. The researcher did not be using the last subscale, intoxicants. The subscales that were used are: (a) mechanics (items 1,2,14, 22): putting a condom on self or other; (b) partner disapproval (items $9,10,16,17,18$ ): use of a condom with a partner's approval; (c) assertive (items 4, 5,6): ability to persuade a partner to use a condom. The researchers used a total of 12 items from the CUSES. Each item has a 5points "strongly disagree" (scored as 1) to "strongly agree" (scored as 5) response format. The scores are summed to yield a total score ranging from 0 to 60 , with higher scores indicating greater condom use self-efficacy. This scale was found to possess adequate liability (Bradford \& Beck, 1991). 
Results

Participants' responses to demographic questions indicated that $24 \%$ were Caucasian, $11 \%$ were African American, $18 \%$ were Hispanic American, $34 \%$ were Asian American, and 5\% were Pacific Islander. All participants had sexual intercourse 1-5 times a week within the past 3 months. Among the 38 participants, 7 (18\%) had history of STD in the past. All participants were between the ages of 18 and 25 years of age.

For the 10 items on the GPSES with the score ranging from a minimum of 10 to the maximum of 40,38 participants $(100 \%)$ reported a minimum score of 22 . Fifty five percent of the participants reported " moderately true" to item number 3 that "It is easy for me to stick to my aims and accomplish my goals". Also, $55 \%$ of the participants reported "true" to item 10 that "I can usually handle whatever comes my way". Seventy one percent of the participants reported "moderately true" to item number 5 that "thanks to my resourcefulness, I know how to handle unforeseen situation". Results indicated that the majority of the participants generally believed that they had high self-esteem and could handle any situation. The GPSES had a mean of 32.11 and SD of 4.336 with a minimum score of 22 and a maximum score of 40.

For the 12 items from the CUSES, 53\% reported that they, "feel confident in their ability to put a condom on their partner" (Item \# 1). Twenty-two participants (58\%) reported that they "feel confident that they could use a condom successfully" (Item \# 12). The findings indicated that a high percentage of respondents felt confident in regard to "putting a condom a self or other" in the "mechanic" subscale of the CUSES. An average of $57 \%$ reported the usage of a condom with a partner's approval in the "partner disapproval" subscale. A high average of $60 \%$ of participants believed that they are 
assertive enough in their ability to persuade their partner to use a condom in the last subscale "assertive" of the CUSES. Responses on the CUSES had a mean of 38.37 and SD of 3.788 with a minimum score of 30 and a maximum score of 51 . There was no statistically significant relationship between the two scales using the Pearson Correlation and there was no correlation between the two variables of self-efficacy and safe sex practice.

No correlation was found between the two variables. This finding could be due to numerous factors. The sample was small and was not randomly selected. The participants may have been young and inexperienced with dating. The participants may have answered, as they believe they should behave; or, they may have answered the way they thought the researcher would want them to answer.

\section{Discussion and Conclusions}

Further study is needed to enhance insights regarding efficacy expectation and the practice of safe sex. Future research might consider how self-efficacy develops in women, and whether strategies suggested by self-efficacy theory such as modeling and role-playing increase women's self-efficacy. Also a larger sample size that was randomly selected would be desirable. The specific age of each participant could be added to the demographic questions. If age groups were determined, intervention programs could be planned that were age-group appropriate. As a clinician it is important to understand why an individual decides to behave in a certain way. Bandura's cognitive theory provides a framework for understanding behavior and how to plan interventions that promote healthy behavior. 
The goal of this study was to support the assumption that individual with high self-efficacy will more likely to practice safe sex. As mentioned earlier in theoretical framework, efficacy expectation is a person's beliefs about her/his capability to produce a particular behavior. Therefore, attitude and behavior changes such as practicing safe sex do not always occur as a result of extensive cognitive processing. An individual has two ways to process a message. The first way is to focus on attitude, subjective norms, and self-efficacy expectations. The second way to process a message is to use more simple decision rules and to focus only on some consequences. It may be that the participants used the second way to process a message and used simple decision rules not to use a condom and did not focus on some of the consequences of not using the condom. Bandura's theory also mentioned that knowledge, incentives, and self-efficacy are all necessary to perform behaviors. Therefore, intervention programs could focus on incentives such as monetary to reward those who practice safe sex and stay clear of STD for 6 months. 
References

Bandura, A. (1977). Self-efficacy: Toward a unifying theory of behavioral change. Psychology Review, 84 (2), 191-215.

Basen-Engquist, K. (1992). Psychological predictors of "safe sex" behaviors in young adults. AIDS Education and Prevention, 4 (2), 120-134.

Bengel, J., Belz-Merk, M., \& Farin, E. (1996). The role of risk perception and efficacy cognitions in the prediction of HIV-related prevention behavior and condom use. Psychology and Health, 11, 505-525.

Brafford, J. L., \& Beck, H. K. (1991). Development and validation of a condom self-efficacy scale for college students. Journal of American College Health, 39, 219-225.

Cecil, H., \& Pinkerton, D. S. (1998). Reliability and validity of a self-efficacy instrument for protective sexual behaviors. Journal of American College Health, 47, 113-121.

Centers for Disease Control and Prevention. (2000). Sexually transmitted diseases surveillance, 2000. Division of STD/HIV Prevention. U.S. Dept. of Health and Human Services, Public Health Service.

Centers for Disease Control and Prevention (2003). STD Surveillance 2003. National Overview of Sexually Transmitted Diseases, 2003. Retrieved April 19, 2005, from http:// www.cdc.gov/std/stats/natoverview.htm

Cobb, K. B. (1997). Communication types and sexual protective practices of college women. Public Health Nurse, 14 (5), 293-301.

Grimley, M. D., Riley, E. G., Bellis, M. J., \& Prochaska, O. J. (1993). Assessing the stages of change and decision-making for contraceptive use for the prevention of 
pregnancy, sexual transmitted diseases, and acquired immunodeficiency syndrome. $\underline{\text { Health }}$ Education Quarterly, 20 (4), 455-470.

Hale, J. P., \& Trumbetta, L. S. (1996). Women's self-efficacy and sexual transmitted disease preventive behaviors. Research in Nursing and Health, 19, 101-110.

Hankins, C. (1998). Changes in pattern of risk. AIDS Care, 10 (2), S147-S153.

Heinrich, B. L. (1993). Contraceptive self-efficacy in college women. Journal of Adolescent Health, 14, 269-276.

Mailbach, E., \& Murphy, A. D. (1995). Conceptualization and measurements. Health Education Research, 10, 37-50.

Morokoff, J. P., Quina, K., Harlow, L. L., Whitmire, L., Grimley, M. D., Gibson, R. P., \& Burkholder, J. G. (1997). Sexual assertiveness scale (SAS) for women: Development and validation. Journal of Personality and Social Psychology, 73 (4), 790-804.

National Vital Statistics Report (2005). Table E. Deaths and Percentage of Total Deaths for The 10 Leading Casauses of Death By Race. National Vital Statistics Reports, $\underline{53}(17), 9$.

O'Leary, A. (1985). Self-efficacy and health. Behavioral Research Therapy, 23 (4), 437-451.

O'Leary, A., Goodhart, F., Jemmott, S. L., \& Boccher-Lattimore, D. (1992). Predictors of safe sex on the college campus: A social cognitive theory analysis. Journal of American college Health, 40, 254-262. 
Schuster, C. (1998). Condom use behavior: An assessment of United States college students' health education needs. Applied Research and Evaluation, 17 (3), 237-254.

Schwarzer, R., \& Jerusalem, M. (1993). The general perceived self-efficacy scale. Retrieved April 19, 2001 from http://www.yorku.ca/facullty/academic/schwarze/engscal.htm

Wulfert, E., \& Wan, K.C. (1993). Condom use: A self-efficacy model. Health Psychology, 12 (5), 346-353. 
Table 1

Appendixes

\begin{tabular}{|c|c|c|c|c|c|}
\hline \multicolumn{6}{|c|}{ Q1 ETHNICITY } \\
\hline & & Frequency & Percent & Valid Percent & Cumulative Percent \\
\hline \multirow{6}{*}{ Valid } & 1 CAUCASIAN & 9 & 23.7 & 23.7 & 23.7 \\
\hline & 2 AFRICAN AMERICAN & 4 & 10.5 & 10.5 & 34.2 \\
\hline & 3 HISPANIC & 7 & 18.4 & 18.4 & 52.6 \\
\hline & 4 ASIAN & 13 & 34.2 & 34.2 & 86.8 \\
\hline & 5 PACIFIC ISLANDER & 5 & 13.2 & 13.2 & 100.0 \\
\hline & Total & 38 & 100.0 & 100.0 & \\
\hline
\end{tabular}

Table 2

Table 3

\begin{tabular}{|r|r|r|r|r|r|}
\hline & & Frequency & Percent & Valid Percent & Cumulative Percent \\
\hline Valid & 11 1-5 & 38 & 100.0 & 100.0 & 100.0 \\
\hline
\end{tabular}

\begin{tabular}{|r|r|r|r|r|r|}
\hline \multicolumn{7}{|c|}{ Q3 EVER HAD STD } \\
\hline \\
& & Frequency & Percent & Valid Percent & Cumulative Percent \\
\hline \multirow{3}{*}{ Valid } & 1 YES & 7 & 18.4 & 18.4 & 18.4 \\
\cline { 2 - 6 } & 2 NO & 31 & 81.6 & 81.6 & 100.0 \\
\cline { 2 - 6 } & Total & 38 & 100.0 & 100.0 & \\
\hline
\end{tabular}

Table 4

\begin{tabular}{|c|c|c|c|c|c|}
\hline & & Frequency & Percent & Valid Percent & Cumulative Percent \\
\hline \multirow{4}{*}{ Valid } & 2 HARDLY TRUE & 1 & 2.6 & 2.6 & 2.6 \\
\hline & 3 MODERATELY TRUE & 13 & 34.2 & 34.2 & 36.8 \\
\hline & 4 EXACTLY TRUE & 24 & 63.2 & 63.2 & 100.0 \\
\hline & Total & 38 & 100.0 & 100.0 & \\
\hline
\end{tabular}


Table 5

Q5 IF SOMEONE OPPOSES ME, I CAN FIND THE MEANS AND WAYS TO GET WHAT I WANT

\begin{tabular}{|l|l|r|r|r|r|}
\hline & Frequency & Percent & Valid Percent & Cumulative Percent \\
\hline \multirow{5}{*}{ Valid } & 2 HARDLY TRUE & 13 & 34.2 & 34.2 & 34.2 \\
\cline { 2 - 6 } & 3 MODERATELY TRUE & 21 & 55.3 & 55.3 & 89.5 \\
\cline { 2 - 6 } & 4 EXACTLY TRUE & 4 & 10.5 & 10.5 & 100.0 \\
\cline { 2 - 6 } & Total & 38 & 100.0 & 100.0 & \\
\hline
\end{tabular}

Table 6

Q6 IT IS EASY FOR ME TO STICK TO MY AIMS AND ACCOMPLISH MY GOALS

\begin{tabular}{|c|c|c|c|c|c|}
\hline & & Frequency & Percent & Valid Percent & Cumulative Percent \\
\hline \multirow{5}{*}{ Valid } & 1 NOT AT ALL TRUE & 1 & 2.6 & 2.6 & 2.6 \\
\hline & 2 HARDLY TRUE & 3 & 7.9 & 7.9 & 10.5 \\
\hline & 3 MODERATELY TRUE & 21 & 55.3 & 55.3 & 65.8 \\
\hline & 4 EXACTLY TRUE & 13 & 34.2 & 34.2 & 100.0 \\
\hline & Total & 38 & 100.0 & 100.0 & \\
\hline
\end{tabular}

Table 7

Q7 I AM CONFIDENT THAT I COULD DEAL EFFICIENTLY WITH UNEXPECTED EVENTS

\begin{tabular}{|l|l|r|r|r|r|}
\hline & Frequency & Percent & Valid Percent & Cumulative Percent \\
\hline \multirow{4}{*}{ Valid } & 2 HARDLY TRUE & 4 & 10.5 & 10.5 & 10.5 \\
\cline { 2 - 6 } & 3 MODERATELY TRUE & 24 & 63.2 & 63.2 & 73.7 \\
\cline { 2 - 6 } & 4 EXACTLY TRUE & 10 & 26.3 & 26.3 & 100.0 \\
\hline & Total & 38 & 100.0 & 100.0 & \\
\hline
\end{tabular}

Table 8

Q8 THANKS TO MY RESOURCEFULNESS, I KNOW HOW TO HANDLE UNFORESEEN SITUATIONS

\begin{tabular}{|r|l|r|r|r|r|}
\hline & Frequency & Percent & Valid Percent & Cumulative Percent \\
\hline \multirow{5}{*}{ Valid } & 2 HARDLY TRUE & 3 & 7.9 & 7.9 & 7.9 \\
\cline { 2 - 7 } & 3 MODERATELY TRUE & 27 & 71.1 & 71.1 & 78.9 \\
\cline { 2 - 7 } & 4 EXACTLY TRUE & 8 & 21.1 & 21.1 & 100.0 \\
\cline { 2 - 6 } & Total & 38 & 100.0 & 100.0 & \\
\hline
\end{tabular}


Table 9

\begin{tabular}{|l|l|r|r|r|r|}
\hline & & Q9 I CAN SOLVE MOST PROBLEMS IF I INVEST THE NECESSARY EFFORT \\
\hline & & Frequency & Percent & Valid Percent & Cumulative Percent \\
\hline \multirow{4}{*}{ Valid } & 2 HARDLY TRUE & 1 & 2.6 & 2.6 & 2.6 \\
\cline { 2 - 6 } & 3 MODERATELY TRUE & 20 & 52.6 & 52.6 & 55.3 \\
\cline { 2 - 7 } & 4 EXACTLY TRUE & 17 & 44.7 & 44.7 & 100.0 \\
\hline & Total & 38 & 100.0 & 100.0 & \\
\hline
\end{tabular}

Table 10

Q10 I CAN REMAIN CALM WHEN FACING DIFFICULTIES BECAUSE I CAN RELY ON MY COPING ABILITIES

\begin{tabular}{|r|l|r|r|r|r|}
\hline & & Frequency & Percent & Valid Percent & Cumulative Percent \\
\hline \multirow{3}{*}{ Valid } & 2 HARDLY TRUE & 7 & 18.4 & 18.4 & 18.4 \\
\cline { 2 - 6 } & 3 MODERATELY TRUE & 18 & 47.4 & 47.4 & 65.8 \\
\cline { 2 - 6 } & 4 EXACTLY TRUE & 13 & 34.2 & 34.2 & 100.0 \\
\cline { 2 - 6 } & Total & 38 & 100.0 & 100.0 & \\
\hline
\end{tabular}

\section{Table 11}

Q11 WHEN I AM CONFRONTED WITH A PROBLEM, I CAN USUALLY FIND SEVERAL SOLUTIONS

\begin{tabular}{|l|l|r|r|r|r|}
\hline & Frequency & Percent & Valid Percent & Cumulative Percent \\
\hline \multirow{5}{*}{ Valid } & 2 HARDLY TRUE & 5 & 13.2 & 13.2 & 13.2 \\
\cline { 2 - 6 } & 3 MODERATELY TRUE & 22 & 57.9 & 57.9 & 71.1 \\
\cline { 2 - 6 } & 4 EXACTLY TRUE & 11 & 28.9 & 28.9 & 100.0 \\
\cline { 2 - 6 } & Total & 38 & 100.0 & 100.0 & \\
\hline
\end{tabular}

Table 12

Q12 IF I AM IN TROUBLE, I CAN USUALLY THINK OF A SOLUTION

\begin{tabular}{|l|l|r|r|r|r|}
\hline & Frequency & Percent & Valid Percent & Cumulative Percent \\
\hline \multirow{4}{*}{ Valid HARDLY TRUE } & 2 & 5.3 & 5.3 & 5.3 \\
\cline { 2 - 6 } & 3 MODERATELY TRUE & 24 & 63.2 & 63.2 & 68.4 \\
\hline & 4 EXACTLY TRUE & 12 & 31.6 & 31.6 & 100.0 \\
\hline
\end{tabular}


Table 13

\begin{tabular}{|l|l|r|r|r|r|}
\hline \multicolumn{1}{|c|}{ Q13 I CAN USUALLY HANDLE WHATEVER COMES MY WAY } \\
\hline & Frequency & Percent & Valid Percent & Cumulative Percent \\
\hline \multirow{5}{*}{ Valid } & 2 HARDLY TRUE & 4 & 10.5 & 10.5 & 10.5 \\
\cline { 2 - 6 } & 3 MODERATELY TRUE & 21 & 55.3 & 55.3 & 65.8 \\
\cline { 2 - 6 } & 4 EXACTLY TRUE & 13 & 34.2 & 34.2 & 100.0 \\
\cline { 2 - 6 } & Total & 38 & 100.0 & 100.0 & \\
\hline
\end{tabular}

Table 14

Q14 I FEEL CONFIDENT IN MY ABILITY TO PUT A CONDOM ON MY PARTNER

\begin{tabular}{|c|c|c|c|c|c|}
\hline & & Frequency & Percent & Valid Percent & Cumulative Percent \\
\hline \multirow{5}{*}{ Valid } & 2 DISAGREE & 2 & 5.3 & 5.3 & 5.3 \\
\hline & 3 UNDECIDED & 7 & 18.4 & 18.4 & 23.7 \\
\hline & 4 AGREE & 9 & 23.7 & 23.7 & 47.4 \\
\hline & 5 STRONGLY AGREE & 20 & 52.6 & 52.6 & 100.0 \\
\hline & Total & 38 & 100.0 & 100.0 & \\
\hline
\end{tabular}

Table 15

Q15 I FEEL CONFIDENT IN MY ABILITY TO DISCUSS CONDOM USAGE WITH ANY PARTNER I MIGHT HAVE

\begin{tabular}{|l|l|r|r|r|r|}
\hline & Frequency & Percent & Valid Percent & Cumulative Percent \\
\hline \multirow{5}{*}{ Valid } & 2 DISAGREE & 3 & 7.9 & 7.9 & 7.9 \\
\cline { 2 - 6 } & 3 UNDECIDED & 1 & 2.6 & 2.6 & 10.5 \\
\cline { 2 - 6 } & 4 AGREE & 11 & 28.9 & 28.9 & 39.5 \\
\cline { 2 - 6 } & 5 STRONGLY AGREE & 23 & 60.5 & 60.5 & 100.0 \\
\hline & Total & 38 & 100.0 & 100.0 & \\
\hline
\end{tabular}


Table 16

Q16 I FEEL CONFIDENT IN MY ABILITY TO SUGGEST USING CONDOMS WITH A NEW PARTNER

\begin{tabular}{|c|c|c|c|c|c|}
\hline & & Frequency & Percent & Valid Percent & Cumulative Percent \\
\hline \multirow{5}{*}{ Valid } & 2 DISAGREE & 3 & 7.9 & 7.9 & 7.9 \\
\hline & 3 UNDECIDED & 1 & 2.6 & 2.6 & 10.5 \\
\hline & 4 AGREE & 10 & 26.3 & 26.3 & 36.8 \\
\hline & 5 STRONGLY AGREE & 24 & 63.2 & 63.2 & 100.0 \\
\hline & Total & 38 & 100.0 & 100.0 & \\
\hline
\end{tabular}

Table 17

Q17 I FEEL CONFIDENT I COULD SUGGEST USING A CONDOM WITHOUT MY PARTNER FEELING DISEASED

\begin{tabular}{|c|c|c|c|c|c|}
\hline & & Frequency & Percent & Valid Percent & Cumulative Percent \\
\hline \multirow{5}{*}{ Valid } & 2 DISAGREE & 2 & 5.3 & 5.3 & 5.3 \\
\hline & 3 UNDECIDED & 2 & 5.3 & 5.3 & 10.5 \\
\hline & 4 AGREE & 12 & 31.6 & 31.6 & 42.1 \\
\hline & 5 STRONGLY AGREE & 22 & 57.9 & 57.9 & 100.0 \\
\hline & Total & 38 & 100.0 & 100.0 & \\
\hline
\end{tabular}

Table 18

Q18 IF I WERE TO SUGGEST USING A CONDOM TO A PARTNER, I WOULD FEEL AFRAID THAT HE WOULD REJECT ME

\begin{tabular}{|l|l|r|r|r|r|}
\hline & Frequency & Percent & Valid Percent & Cumulative Percent \\
\hline \multirow{5}{*}{ 1 STRONGLY DISAGREE } & 20 & 52.6 & 52.6 & 52.6 \\
\hline 2 DISAGREE & 12 & 31.6 & 31.6 & 84.2 \\
\cline { 2 - 7 } & 3 UNDECIDED & 1 & 2.6 & 2.6 & 86.8 \\
\cline { 2 - 7 } & 4 AGREE & 4 & 10.5 & 10.5 & 97.4 \\
\cline { 2 - 6 } & 5 STRONGLY AGREE & 1 & 2.6 & 2.6 & 100.0 \\
\hline & Total & 38 & 100.0 & 100.0 & \\
\hline
\end{tabular}

Table 19

Q19 IF I WERE UNSURE OF MY PARTNER'S FEELINGS ABOUT USING CONDOMS, I WOULD NOT SUGGEST USING ONE

\begin{tabular}{|l|l|l|l|l|l|}
\hline & & Frequency & Percent & Valid Percent & Cumulative Percent \\
\hline
\end{tabular}




\begin{tabular}{|c|c|c|c|c|c|}
\hline \multirow{6}{*}{ Valid } & I STRONGLY DISAGREE & 23 & 60.5 & 60.5 & 60.5 \\
\hline & 2 DISAGREE & 11 & 28.9 & 28.9 & 89.5 \\
\hline & 3 UNDECIDED & 2 & 5.3 & 5.3 & 94.7 \\
\hline & 4 AGREE & 1 & 2.6 & 2.6 & 97.4 \\
\hline & 5 STRONGLY AGREE & 1 & 2.6 & 2.6 & 100.0 \\
\hline & Total & 38 & 100.0 & 100.0 & \\
\hline
\end{tabular}

Table 20

Q20 I FEEL CONFIDENT I COULD GRACEFULLY REMOVE AND DISPOSE OF A CONDOM WHEN WE HAVE INTERCOURSE

\begin{tabular}{|l|l|r|r|r|r|}
\hline & & Frequency & Percent & Valid Percent & Cumulative Percent \\
\hline \multirow{5}{*}{ 2 DISAGREE } & 5 & 13.2 & 13.2 & 13.2 \\
\cline { 2 - 6 } & 3 UNDECIDED & 2 & 5.3 & 5.3 & 18.4 \\
\cline { 2 - 6 } & 4 AGREE & 13 & 34.2 & 34.2 & 52.6 \\
\cline { 2 - 6 } & 5 STRONGLY AGREE & 18 & 47.4 & 47.4 & 100.0 \\
\hline
\end{tabular}

Table 21

Q21 I WOULD NOT FEEL CONFIDENT SUGGESTING USING CONDOMS WITH A NEW PARTNER BECAUSE I WOULD BE AFRAID HE WOULD THINK I'VE HAD A PAST HOMOSEXUAL EXPERIENCE

\begin{tabular}{|c|c|c|c|c|c|}
\hline & & Frequency & Percent & Valid Percent & Cumulative Percent \\
\hline \multirow{5}{*}{ Valid } & $\begin{array}{l}1 \text { STRONGLY } \\
\text { DISAGREE }\end{array}$ & 23 & 60.5 & 60.5 & 60.5 \\
\hline & 2 DISAGREE & 10 & 26.3 & 26.3 & 86.8 \\
\hline & 3 UNDECIDED & 2 & 5.3 & 5.3 & 92.1 \\
\hline & 4 AGREE & 3 & 7.9 & 7.9 & 100.0 \\
\hline & Total & 38 & 100.0 & 100.0 & \\
\hline
\end{tabular}


Table 22

Q22 I WOULD NOT FEEL CONFIDENT SUGGESTING USING CONDOMS WITH A NEW PARTNER BECAUSE I WOULD BE AFAID HE WOULD THINK I HAVE A STD

\begin{tabular}{|r|l|r|r|r|r|}
\hline & Frequency & Percent & Valid Percent & Cumulative Percent \\
\hline \multirow{5}{*}{$\begin{array}{l}\text { 1 STRONGLY } \\
\text { DISAGREE }\end{array}$} & 22 & 57.9 & 57.9 & 57.9 \\
\cline { 2 - 6 } & 2 DISAGREE & 12 & 31.6 & 31.6 & 89.5 \\
\cline { 2 - 6 } & 3 UNDECIDED & 2 & 5.3 & 5.3 & 94.7 \\
\cline { 2 - 6 } & 4 AGREE & 2 & 5.3 & 5.3 & 100.0 \\
\hline
\end{tabular}

Table 23

Q23 I WOULD NOT FEEL CONFIDENT SUGGESTING USING CONDOMS WITH A NEW PARTNER BECAUSE I WOULD BE AFRAID HE WOULD THINK I THOUGHT HE HAD A STD

\begin{tabular}{|r|l|r|r|r|r|}
\hline & Frequency & Percent & Valid Percent & Cumulative Percent \\
\hline \multirow{5}{*}{$\begin{array}{l}\text { 1 STRONGLY } \\
\text { DISAGREE }\end{array}$} & 21 & 55.3 & 55.3 & 55.3 \\
\cline { 2 - 7 } & 2 DISAGREE & 12 & 31.6 & 31.6 & 86.8 \\
\cline { 2 - 7 } & 3 UNDECIDED & 2 & 5.3 & 5.3 & 92.1 \\
\cline { 2 - 7 } & 4 AGREE & 3 & 7.9 & 7.9 & 100.0 \\
\hline
\end{tabular}

Table 24

Q24 I FEEL CONFIDENT IN MY ABILITY TO PUT A CONDOM ON MY PARTNER QUICKLY

\begin{tabular}{|c|c|c|c|c|c|}
\hline & & Frequency & Percent & Valid Percent & Cumulative Percent \\
\hline \multirow{6}{*}{ Valid } & 1 STRONGLY DISAGREE & 1 & 2.6 & 2.6 & 2.6 \\
\hline & 2 DISAGREE & 3 & 7.9 & 7.9 & 10.5 \\
\hline & 3 UNDECIDED & 5 & 13.2 & 13.2 & 23.7 \\
\hline & 4 AGREE & 16 & 42.1 & 42.1 & 65.8 \\
\hline & 5 STRONGLY AGREE & 13 & 34.2 & 34.2 & 100.0 \\
\hline & Total & 38 & 100.0 & 100.0 & \\
\hline
\end{tabular}


Table 25

\begin{tabular}{|l|l|r|r|r|r|}
\hline \multicolumn{2}{|c|}{ Q25 I FEEL CONFIDENT THAT I COULD USE A CONDOM SUCCESSFULLY } \\
\hline & & Frequency & Percent & Valid Percent & Cumulative Percent \\
\hline \multirow{4}{*}{ Valid } & 3 UNDECIDED & 3 & 7.9 & 7.9 & 7.9 \\
\cline { 2 - 6 } & 4 AGREE & 13 & 34.2 & 34.2 & 42.1 \\
\cline { 2 - 6 } & 5 STRONGLY AGREE & 22 & 57.9 & 57.9 & 100.0 \\
\cline { 2 - 7 } & Total & 38 & 100.0 & 100.0 & \\
\hline
\end{tabular}

